SYSTEMATIC REVIEW

\title{
Construction safety research in the United States: targeting the Hispanic workforce
}

\section{J Brunette}

See end of article for authors' affiliations .....................

Correspondence to: Professor Maria J Brunette, Department of Work Environment, University of Massachusetts-Lowell, One University Avenue, Lowell, MA 01854, USA;

Maria_Brunette@uml.edu
While it is known that Hispanics have a continuous growing participation in the construction workforce and that their fatal and non-fatal occupational injuries are higher than any other ethnic group, very little construction safety and health research has been conducted in the United States. Research that focuses on safety and health of Hispanic workers employed in the construction industry might prove beneficial in reducing injuries and promoting safe and decent workplaces for all.

The purpose of this article was twofold. First, to propose a research agenda where topics such as surveillance, intervention research on high risk occupations, intervention effectiveness evaluation, design and development of effective and appropriate safety training and educational materials, and the socioeconomic impact of injuries and illnesses, are investigated among the Hispanic construction workforce. Second, to present relevant aspects inherent to this particular population that need to be incorporated into the design and development stages of any safety and health research initiative. They include the occupational, social, economic, and cultural background of Hispanic workers; use of a participatory approach, proper selection and use of translation methods; and conducting collaborative research. Certain limitations and challenges related to the availability of resources for conducting safety and health research on Hispanic workers are further discussed.

\section{OVERVIEW}

Construction, one of the largest industries in the United States with $7.03 \%$, or 9.4 million, of all the civilian labor force, is one of the most dangerous industries, accounting for $20.3 \%$, or 1121 , of all occupational deaths in the year $2002 .{ }^{1}$ It also has one of the highest rates of occupational injuries and illnesses compared with other industries and with construction in other developed countries. During the period from 1980 through 1995, at least 17000 workers died from injuries suffered on the job. ${ }^{2}$ The dynamic, temporary, and hazardous nature of the construction industry poses a challenge for conducting research studies. Construction workers perform several physically demanding tasks with varying types and levels of exposures (see appendix 1). They are expected to change employers and work sites frequently due to the transitory nature of construction workplaces and projects. Due to advances in technology, most of the tasks on a construction site have seen changes with more powerful and complex tools and machinery. Construction workers are also believed to own a unique "cultural" mindset towards the perceptions of different levels of hazards. All of these aspects need to be considered in the design and implementation of any strategy for injury prevention in the construction industry.

To complicate the situation, let us consider the explosive growth of construction immigrant workers, where the vast majority comes from Latin American countries. Besides agriculture, the construction industry is the top employer for these immigrant workers who usually lack trade related skills and, more significantly, language skills (approximately one third of Hispanic construction workers speak only Spanish). ${ }^{3}$ These workers also bring with them a unique sociocultural background that deserves to be taken into account. Without doubt, all these factors represent a challenge for conducting safety research involving this population. To date, very little construction safety and health research has been conducted involving Hispanic workers. While there might be some ongoing research projects targeted to construction Hispanic workers' safety, their dissemination process may be quite poor. Lack of publication in peer reviewed journals and in other relevant sources of information gives the impression that minimal or no research activities targeted to the Hispanic construction workforce in the United States are being undertaken by the research community. The objective of this article is twofold. First, to emphasize the need to incorporate the use of a macro approach into safety research among Hispanic construction workers; and second, to present an agenda that may effectively guide the research community in its injury prevention efforts.

\section{Demographic changes in the United States: the Hispanic workforce}

Over the past two decades the United States has experienced one of the largest waves of immigration in its history. These immigration trends have produced the most dramatic changes in the ethnic composition of the United States population since the first decades of the past century where now the source countries of these immigrants to the United States have shifted dramatically to Latin America and Asia. The United States Immigration and Naturalization Service (2001) reports that there are 34.7 million foreign-born persons in the United States, of whom approximately 7 million are undocumented. Including both legal admissions and illegal entrants who later receive amnesty and legal residence, the United States receives approximately 900000 immigrants each year. ${ }^{4} 5$

Today, Hispanics are the fastest growing ethnic group in the United States. Hispanics include a large proportion of immigrants from Latin America as well as people whose families have lived within the current boundaries of the United States for many generations. Although they come from different countries, the use of Spanish language is what

Abbreviations: OSHA, Occupational Safety and Health Administration; SHTG, Susan Harwood Training Grant 
brings them together. In 2000, there were 35.3 million Hispanics in the United States, a 58\% increase over the 22.4 million recorded in the 1990 census. This significantly differs from non-Hispanics who had a population increase of less than $9 \%$ during the same time period. ${ }^{67}$ At the same time, the Hispanic share of the United States workforce grew from $5.9 \%$ in 1980 to $20 \%$ in 2000 and is expected to increase $36 \%$ in the next 10 years compared with an increase in the national workforce of only $12 \%$. Despite significant undercounting issues, as reported by the National Research Council, ${ }^{8}$ the census reports that Hispanics make up 13\% of the population, and estimates that one out of four persons living in the United States will be of Hispanic origin by 2050.

\section{Hispanic workers and the construction industry}

In the United States, construction has a larger share of Hispanic workers than any industry (18\%), except agriculture $(37 \%)$. The participation of Hispanics in construction has been continuously growing. For instance, during 1995 and 1996 Hispanics represented $10 \%$ of all workers in the construction industry; in 2001, the percentage reached $18 \%$ or 1.3 million, representing an increase of more than $100 \%$ for the last 10 years. $^{2}$ The composition of the Hispanic construction workers includes 55\% Mexicans, 20\% Mexican Americans/Chicanos, 14\% Central/South Americans, 3\% Puerto Ricans, 3\% Cubans, and 5\% Hispanics of other countries of origin. ${ }^{9}$

Hispanic workers are in some ways underrepresented and in other ways overrepresented sectors of the workforce with regard to safety at work. They are underrepresented in the ways that the scientific, research, and academic community can reach them with appropriate safety research, education, and information; they are overrepresented in their rates of work related fatal and non-fatal injuries and in their participation in high hazard industries. ${ }^{10}$ Hispanics work in some of the most dangerous industries and have higher fatal and non-fatal occupational injuries than any other ethnic group in the United States. ${ }^{4{ }^{11-13}}$ According to the Bureau of Labor Statistics data, the fatality rate for Hispanics in all industries-5.2 deaths per 100000 workers-is about 20\% higher than the rates for white and black workers, which are 4.4 and 4.1 deaths per 100000 respectively. Considering the different legal, cultural, and economic pressures faced by Hispanic workers, it is likely that underreporting of occupational injuries and illnesses by both workers and employers occurs in the construction industry. ${ }^{4}$ Drywall, tile, and concrete workers as well as painters, roofers, and laborers are the occupations with a significant participation of the Hispanic workforce (see table 1). When looking at injuries among the fatally injured Hispanic workers from 1995 to 2000, for example, construction laborers had the highest number of deaths (490), in which $37 \%$ of the primary fatal injury event was falls to a lower level. Unfortunately, comprehensive data on fatal and non-fatal injuries for the major construction occupations is not available for Hispanic workers.

\section{DISCUSSION \\ Current safety and health research among Hispanic construction workers}

To date, very little construction safety research targeted to the Hispanic workforce has been carried out. According to the United States National Institute of Occupational Safety and Health Compendium of Construction Research, ${ }^{8}$ out of its 106 research projects funded during 2002, only one project had Hispanic construction workers as its major focus and a second project focused on the demographics of the construction workforce. These projects, conducted at the Center to Protect Workers' Rights, have examined data at the national
Table 1 Hispanic construction workers as percentage of selected occupations, 19982000 average (Center to Protect Workers' Rights, 2002)

\begin{tabular}{ll}
\hline Occupation & $\%$ \\
\hline Drywall installer & 33 \\
Tiler & 31 \\
Concrete worker & 27 \\
Painter & 26 \\
Roofer & 23 \\
Laborer/helper & 21 \\
Bricklayer, mason & 18 \\
Not classified & 17 \\
Welder & 16 \\
Carpet layer & 16 \\
Repairer & 14 \\
Plumber & 12 \\
Truck driver & 12 \\
Heating/air conditioning mechanic & 11 \\
Electrical worker & 9 \\
Operating engineer & 9 \\
Foreman & 8 \\
Administration support & 6 \\
Elevator operator & 5 \\
Manager & 5 \\
\hline
\end{tabular}

level. Two other studies have examined data at the state level $^{12}{ }^{14}$ : one focused on fatal occupational injuries among Hispanic construction workers in Texas and the other one was a qualitative study of hazards faced by Hispanic construction workers in the Triangle Area of North Carolina. Funding sources for these two last projects have not been clearly defined. It should also be noted that through the Susan Harwood Training Grants (SHTGs), a program established in 2000 by the United States Occupational Safety and Health Administration (OSHA), funding has been provided for safety and health education for the American workforce. A review of the first three years of SHTG funded programs shows that 11 out of 22 new construction related grants were targeted to Hispanic workers. This shows the significant recognition and interest that these grantees have towards reaching Hispanic workers with safety and health education and training materials. However, there is a lack of dissemination of results via relevant communication channels not only to the researchers but also to the practitioners. There is also a lack of a centralized project evaluation process from which future researchers and practitioners can benefit, thus minimizing the duplication of efforts. It is also expected that fewer projects focused on Hispanic construction workers will be funded in the following years considering that the OSHA budget for workers' health and safety training for 2003 (\$4.2 million) suffered a 64\% cutback compared with 2002 (\$11.4 million).

\section{Characteristics of research needed}

Embarking on safety research targeted to Hispanic construction workers is definitely not a simple task. Four major aspects are highly relevant to the nature of the Hispanic workforce and that may contribute to the effectiveness of research initiatives are discussed as follows.

\section{(1) Understanding background of Hispanic workforce}

A clear understanding of the occupational, socioeconomic, and cultural background of the Hispanic workforce is critical. Hispanic workers bring with them a strong and diverse background that has an effect on their work attitudes and expectations. Such a background will have a significant role throughout all the stages of a research project including the 
design, development, implementation, and evaluation stages. In general, Hispanic workers come to the United States with poor understanding of health and safety, little or no participation in building (or other) trades, and little or no governmental enforcement of safety regulations. Certain work related experiences in their countries of origin will also be key determinants of these workers' level of safety awareness. These include working under poor physical environments, little or no safety and health training, being exposed to dangerous tools, machines and equipment, abusive supervisors, and lack of appropriate personal protective equipment, among others. Hispanic workers also bring with them varied histories, cultural sensibilities, strong health beliefs, and a different cultural background compared with non-Hispanic workers. English is not the first language of Hispanic workers and, consequently, their understanding of educational materials about safety at work will be significantly lower in comparison with native English speakers. This problem is aggravated by the fact that a small, but significant, portion of Hispanic workers are illiterate in their own language. The mode of incorporation into the United States might also shape Hispanic workers' experiences. ${ }^{15}$ Once established here, Hispanic workers could experience fears based on immigration status and strong economic pressures to stay employed. Serious underreporting levels of both fatal and non-fatal injuries might occur in an attempt to keep positive relationships with employers. As stated by the National Research Council, ${ }^{6}$ Hispanic workers are "less likely to report violations of their working rights or occupational injuries because they might lose their pay or their job". The author proposes here the use of a macro approach to occupational safety research among Hispanic construction workers that looks inside and outside the work environment. Evaluation inside the work environment should consider five elements: tasks and tools, technology, organizational factors, physical environment, and individual or personal factors. ${ }^{16}$ These factors and their interactions should be cautiously analyzed and incorporated into the study design. Factors outside the work system such as the social, economic, and cultural background need also to be included.

\section{(2) Participatory approach}

Brown suggested the use of a workers' participatory approach when developing safety and health training materials for Hispanic workers. ${ }^{4}$ The involvement of workers in the design, development, and continuous evaluation stages of a research effort is important considering that creative thinking can come from the workers themselves. Establishing a research environment that is "worker friendly" in the sense that workers' ideas, perceptions, and experiences are welcome and taken into account might lead to appropriate and reliable results.

\section{(3) Translation methods}

One of the critical factors in conducting research with nonEnglish speaking populations is the design and development of linguistic and culturally appropriate materials that could be easily understood by the target audience. Thus, selection of the translation method will play a critical part. Unfortunately, there is no consensus about the best translation method but it seems that a simple direct translation of safety materials might communicate incorrect meanings. In general, the quality of existing materials that have been used and translated into Spanish is varied. Large portions of them either suffer from poor and/or erroneous translations or are overly technical translations not easily understood by the target audience. ${ }^{6}$ Back translation is perhaps the method most widely accepted since it matches closely the original version. However, this procedure does not guarantee that the materials translated will be easily understood by the target audience. It has been suggested that when the aim is conceptual equivalence, the preferable translation method to use is decentering.$^{17}{ }^{18}$ In the decentering method the materials in the source language are not considered finalized until the whole translation process has come to an end. Decentering involves a continuous revision process where source language materials are first translated into the target language and remain subject to revisions until conceptual clarity and appropriate grammatical structures have been achieved. By revising both versions when language discrepancies occur, literal translations are avoided and "conceptual equivalence" is achieved. A basic difference between back translation and decentering is that the later "considers both languages equally important in the production of materials, while back translation considers the original language the standard against which the target version is to be compared" ${ }^{19}$ Further research needs to be conducted on the effectiveness and appropriateness of materials translated via this technique.

\section{(4) Need for collaborative research}

Safety issues related to Hispanic construction workers needs to be examined from a cross disciplinary perspective. This implies participation of researchers from a wide range of research and academic backgrounds including engineering, safety, occupational health, epidemiology, social sciences, and others. As mentioned earlier, the complex environment where Hispanics live and work demands the use of a holistic approach in any attempt to promote health and safety among them. An integrated approach towards safety that includes not only work related factors but also socioeconomic and cultural factors might prove beneficial.

There is a need to conduct collaborative efforts between the research community and unions, community development organizations, and advocacy groups. Researchers need to build partnerships with these organizations for two main reasons. First, these groups have developed, to some extent, a relationship of "trust" between their representatives and the working community. Second, it is most likely that these groups will have better access to the working class, thus facilitating the process of accessing research participants.

\section{Need for a research agenda}

What should be the priority research areas aimed to promote decent and safe jobs for Hispanics employed in the construction industry? Although the answer might seem simple and clear, it is worth mentioning that safety and health research in the construction industry is considered a relatively "young" research field in the United States when compared with other safety and health research fields such as manufacturing. Inclusion of the Hispanic workforce into any construction safety research attempt represents not only a challenging task but also an important and significant step towards the advancement of occupational safety research in the United States. Five areas within this research agenda are presented as follows.

\section{(1) Surveillance}

Research is needed to precisely determine where Hispanics are working, their conditions of work, and the extent and severity of injuries among these workers. While safety research in construction has evolved from this initial surveillance stage to an intervention and diffusion stage, research is required to design and develop appropriate surveillance research methods to examine the Hispanic construction workforce. Researchers need to be aware that lack of appropriate data and misleading sources of information present a serious problem in any attempt to conduct research on this target population. Without having an accurate 
"starting point" to rely on, measurement of progress in safety research will be difficult to accomplish. As mentioned earlier, underreporting of fatal and non-fatal injuries also presents a research challenge since Hispanic workers might have fears of loosing their pay, their jobs, and even their opportunity to remain in the United States based on their immigrant status.

(2) Intervention research on high risk occupations for Hispanic construction workers

Interventions addressing critical safety issues of certain Hispanic occupational groups within the construction industry are needed. They should consider issues such as the occupations exposed to the highest risks, the causes of fatal and non-fatal injuries among them, the extent to which those injuries could have been prevented, and the appropriateness of research methods that will be employed in conducting the intervention research. Construction looses more workers to traumatic injury deaths than any other major industrial sector. The leading causes of death among construction workers are falls from elevations, motor vehicles crashes, electrocution, machines (being caught-in/being crushed-by), and being struck by falling objects. ${ }^{3}$ Falls account for $31 \%$ and $21 \%$ of fatal (falls from roofs and falls from scaffolds) and non-fatal (falls to the same level and falls from ladders) injuries in construction. Among the fatally injured Hispanic workers from 1995-2000, the occupation with the highest number of fatal injuries was construction laborers (490 fatalities). In terms of event, falls to a lower level account for $16 \%$ of fatal work injuries for Hispanic men. ${ }^{13}$ Intervention research aiming to reduce fatal and nonfatal injuries among Hispanic construction laborers, roofers, and carpenters is a critical need. A better understanding of the real causes and the extent of the problem of the construction "big" hazards will contribute to the design of effective interventions with positive implications for injury prevention among the Hispanic workforce. In addition, intervention research aimed to reduce and control other hazards such as musculoskeletal and ergonomics related hazards is also needed. Research on the interaction between physical and psychosocial stressors at the workplace might also prove beneficial.

\section{(3) Intervention effectiveness evaluation}

Considering that there has been very little intervention research conducted among Hispanic workers, it is expected that fewer or no research initiatives on evaluating the effectiveness of such interventions have been carried out. In training intervention research, for example, there has been little systematic evaluation of the effectiveness of safety training programs specifically targeted to construction workers and, to date, no study has focused on the evaluation of safety training programs targeted specifically to Hispanic construction workers. ${ }^{20}$ Evaluating the effectiveness of an intervention research effort is a crucial step that researchers will need to incorporate sooner or later into their research plans.

\section{(4) Need for effective and appropriate safety training and educational materials}

Provision of adequate training and education on health and safety is now recognized as one of the most critical factors in reducing and preventing injuries. Researchers should recognize that better educated workers will be more aware of safety and health at their workplaces. The "better" term does not refer only to quantity but most importantly, to the quality of education. Unfortunately, there is a great variability in the quality of the safety and health materials currently available in Spanish. Most of the few existing materials have considered language translation as the only criteria for material development. In general, it is recognized that effective safety and health training and education of Hispanic workers should include programs that are developed in a language that is familiar to the workers, should be delivered in a learner centered environment, should be culturally sensitive, and should be accompanied by a true commitment to safety. ${ }^{351617}$ Developing an effective way of disseminating materials on construction safety and health and assessing its impact should also prove beneficial.

(5) Socioeconomic impact of injuries and illnesses While the invisible and hidden social and economic impact of occupational injuries is a relatively new research topic, it has been recognized that the effects of work related injuries in construction are complex and go beyond the physical boundaries of the worker. ${ }^{21}$ The existing research has focused on the traditional facets of economic costs ignoring the role that social, cultural, and other "hidden" economic factors play in worker's health and safety. Overall, identification of the magnitude of injuries and diseases for employers, workers and families, government, and society has not been well documented. There is a need to investigate the long term social and economic effects on Hispanic construction workers and their families that originate from work related injuries. This impact of occupational injuries and illnesses is expected to be higher considering their vulnerable living and working conditions.

\section{Research limitations and challenges: availability of funding sources and researchers}

The priorities areas outlined above might suggest ideas of the direction in which the research community needs to move if the objectives of reducing injuries and providing safe workplaces for Hispanic construction workers are to be achieved. The critical aspect now is whether an adequate number of committed researchers and sufficient resources are currently available. Since little attention and awareness has been

\section{Key points}

- Construction is one of the most dangerous industries. In the past fatality rates for Hispanic workers in the construction industry have been consistently higher than the overall national fatality rate.

- To date, very little construction safety and health research has been conducted among Hispanic workers. Considering that Hispanics have higher fatal and non-fatal occupational injuries than any other ethnic group in the United States, and the growing participation of the Hispanic workforce in construction (18\%), the need to conduct safety and health research focusing on this particular population becomes obvious.

- Focusing on understanding Hispanic workers' occupational, social, economic, and cultural background; using a participatory approach and proper translation methods; and conducting collaborative research, are characteristics that any construction safety and health research initiative should take into account.

- In this study, a research agenda that incorporates surveillance, intervention research on high risk occupations, intervention effectiveness evaluation, design, and development of effective and appropriate safety training and educational materials, and understanding socioeconomic impact of injuries was proposed. 
coming from the research community, it is then relevant to ask: Should construction safety and health researchers focus on the Hispanic workforce? And if so, Why? The answer to the first question is simple: yes! The answer to the second is a complex one. It depends on how the researcher wants to look at the problem. The more people working on the problem and addressing the issues, the higher the impact that the research community will have on promoting safe workplaces for this segment of the United States workforce. Although there are very few researchers committed and embarked on this particular research area, it is expected that external forces and motives such as the ongoing demographic changes in the construction workforce, the alarming rates of fatal and nonfatal injuries among Hispanic construction workers, and pressure from advocacy and non-profit groups as well as from community organizations will contribute enough to capture the attention and interest of the research community; this will generate positive outcomes in terms of development of research initiatives targeted to the Hispanic workforce.

There is uncertainty with regard to sources of funding opportunities to conduct this particular type of research. Budgets from federal agencies are shrinking and their program areas are continuously changing. On the other hand, other potential funding sources (for example, foundations) might also take time to recognize the need to incorporate safety and health of immigrant workers in their program areas. The author believes that safety and health research of Hispanic workers in the United States is a research area that has lots of potential to growth, however, its growth will depend first on who will be conducting the research and how well the research is approached, and second on what support systems are in place to promote the development and implementation of such significant research.

\section{REFERENCES}

1 US Bureau of Labor Statistics. Census of fatal occupational injuries. Washington, DC: US Census Bureau, 2003.

2 National Institute of Occupational Safety and Health. Construction. [Online.] Available at: http://www.cdc.gov/niosh/. Washington, DC: NIOSH, 2003.

3 Center to Protect Workers' Rights-CPWR. The construction chart book. Silver Spring, MD: Center to Protect Workers' Rights, 2002.

4 Brown MP. An Examination of occupational safety and health materials currently available in Spanish for workers as of 1999. National Research Council. Safety is seguridad. Washington, DC: National Academy of Sciences, 2003.

5 Edmonston B. Statistics on US immigration - an assessment of data needs for future research. Washington, DC: National Academy Press, 1996.

6 National Research Council. Safety is seguridad. Washington, DC: National Academy of Sciences, 2003.

7 US Bureau of Labor Statistics. The Hispanic population of the United States. Washington, DC: US Census Bureau, 2000.

8 National Research Council. Speaking of health: assessing health communication strategies for diverse populations. Washington, DC: National Academy Press, 2002.

9 Platner JW, Dong S. Hispanic workers in the US construction industry. New Orleans: AlHCE, 2001

10 O'Connor T. Reaching Spanish-speaking workers and employers with occupational safety and health information. National Research Council. Safety is seguridad. Washington, DC: National Academy of Sciences, 2003.

11 Christopher B. Hispanic worker fatalities rise; improved training is needed. Professional Safety 2002;46(12)

12 O'Connor T, Gildner P, Easter M. Immigrant workers at risk: a qualitative study of hazards faced by Latino immigrant construction workers in the Triangle Area of North Carolina. Durham, NC: North Carolina Occupational Safety and Health Project, 2000.

13 Richardson S, Ruser J, Suarez P. Hispanic workers in the United States: an analysis of employment distributions, fatal occupational injuries, and non-fatal occupational injuries and illnesses. National Research Council. Safety is seguridad. Washington, DC: National Academy of Sciences, 2003.

14 Fabrega V, Starkey S. Fatal occupational injuries among Hispanic construction workers of Texas, 1997 to 1999 . Human and Ecological Risk Assessment 2001;7:1869-83.

15 Suárez-Orozco MM, Páez MM. Latinos: remaking America. Los Angeles, CA: University of California Press, 2002

16 Smith MJ, Carayon-Sainfort P. A balance theory of job design for stress reduction. International Journal of Industrial Ergonomics 1989;4:67-9.

\section{APPENDIX}

Primary hazards encountered in skilled construction trades $^{21}$

\begin{tabular}{|c|c|}
\hline Occupation & Hazards \\
\hline Brickmasons & $\begin{array}{l}\text { Cement dermatitis, awkward postures, } \\
\text { heavy loads }\end{array}$ \\
\hline Stonemasons & $\begin{array}{l}\text { Cement dermatitis, awkward postures, } \\
\text { heavy loads }\end{array}$ \\
\hline Hard tile setters & $\begin{array}{l}\text { Vapor from bonding agents, dermatitis, } \\
\text { awkward postures }\end{array}$ \\
\hline Carpenters & Wood dust, heavy loads, repetitive motion \\
\hline Drywall installers & $\begin{array}{l}\text { Plaster dust, walking on stilts, heavy loads, } \\
\text { awkward postures }\end{array}$ \\
\hline Electricians & $\begin{array}{l}\text { Heavy metals in solder fumes, awkward } \\
\text { posture, heavy loads, asbestos dust }\end{array}$ \\
\hline $\begin{array}{l}\text { Electrical power installers } \\
\text { and repairers }\end{array}$ & $\begin{array}{l}\text { Heavy metals in solder fumes, heavy loads, } \\
\text { asbestos dust }\end{array}$ \\
\hline Painters & $\begin{array}{l}\text { Solvent vapors, toxic metals in pigments, } \\
\text { paint additives }\end{array}$ \\
\hline Paperhangers & Vapor from glue, awkward postures \\
\hline Plasterers & Dermatitis, awkward postures \\
\hline Plumbers & Lead fumes and particles, welding fumes \\
\hline Pipefitters & $\begin{array}{l}\text { Lead fumes and particles, welding fumes, } \\
\text { asbestos dust }\end{array}$ \\
\hline Steamfitters & Welding fumes, asbestos dust \\
\hline Carpet layers & $\begin{array}{l}\text { Knee trauma, awkward postures, glue and } \\
\text { glue vapor }\end{array}$ \\
\hline Soft tile installers & Bonding agents \\
\hline $\begin{array}{l}\text { Concrete and terrazzo } \\
\text { finishers }\end{array}$ & Awkward postures \\
\hline Glaziers & Awkward postures \\
\hline Insulation workers & Asbestos, synthetic fibers, awkward postures \\
\hline $\begin{array}{l}\text { Paving, surfacing and } \\
\text { tamping equipment } \\
\text { operators }\end{array}$ & $\begin{array}{l}\text { Asphalt emissions, gasoline and diesel } \\
\text { engine exhaust, heat }\end{array}$ \\
\hline Rail and track laying & Silica dust, heat \\
\hline $\begin{array}{l}\text { equipment operators } \\
\text { Roofers }\end{array}$ & Roofina tar heat working at heiahts \\
\hline $\begin{array}{l}\text { Rooters } \\
\text { Sheetmetal duct installers }\end{array}$ & Awkward postures, heavy loads, noise \\
\hline Structural metal installers & $\begin{array}{l}\text { Awkward postures, heavy loads, working at } \\
\text { heights }\end{array}$ \\
\hline Welders & Welding emissions \\
\hline Solderers & Metal fumes, lead, cadmium \\
\hline Drillers, earth, rock & Silica dust, whole body vibration, noise \\
\hline Air hammer operators & Noise, whole body vibration, silica dust \\
\hline Pile driving operators & Noise, whole body vibration \\
\hline Hoist and winch operators & Noise, lubricating oil \\
\hline $\begin{array}{l}\text { Crane and tower } \\
\text { operators }\end{array}$ & Stress, isolation \\
\hline $\begin{array}{l}\text { Excavating and loading } \\
\text { machine operators }\end{array}$ & $\begin{array}{l}\text { Silica dust, histoplasmosis, whole body } \\
\text { vibration, heat stress, noise }\end{array}$ \\
\hline $\begin{array}{l}\text { Grader, dozer, and } \\
\text { scraper operators }\end{array}$ & $\begin{array}{l}\text { Silica dust, whole body vibration, heat, } \\
\text { noise }\end{array}$ \\
\hline $\begin{array}{l}\text { Highway and street } \\
\text { construction workers }\end{array}$ & $\begin{array}{l}\text { Asphalt emissions, heat, diesel engine } \\
\text { exhaust }\end{array}$ \\
\hline Truck and tractor & Whole body vibration, diesel engine \\
\hline equipment operators & \\
\hline Demolition workers & Asbestos, lead, dust, noise \\
\hline Hazardous waste workers & Heat, stress \\
\hline
\end{tabular}

17 Behling O, Law KS. Translating questionnaires and other research instruments: problems and solutions. Thousand Oaks, CA: Sage Publications, 2000.

18 Werner O, Campbell DT. Translating, working through interpreters and the problem of decentering. In: Naroll R, Cohen R, eds. A handbook of method in cultural anthropology. New York: American Museum of Natural History, 1970.

19 Marin G, Van Oss-Marin B. Research with Hispanic populations, Applied Social Research Methods Series. Thousand Oaks, CA: Sage Publications, 1991, vol 23

20 Dong S, Schneider S, Chowdhurry R, et al. Training effects on work-related injuries among construction laborers. Proceedings of the 3rd NIOSH National Occupational Injury Research Symposium. Pittsburgh, PA, 2003.

21 Ringen K, Seegal J, Weeks JL. Occupational safety and health in the construction industry. Encyclopedia of occupational health and safety. 4th Ed. Vol III. Geneva: International Labor Organization, 1998. 